\title{
repisälud
}

This is the peer reviewed version of the following article:

Mazzanti, A., Underwood, K., Nevelev, D., Kofman, S., \& Priori, S. G. (2017). The new kids on the block of arrhythmogenic disorders: Short QT Syndrome and early repolarization. Journal of Cardiovascular Electrophysiology, 28(10), 1226-1236. doi:10.1111/jce.13265

which has been published in final form at: https://doi.org/10.1111/jce.13265 


\section{The New Kids on the Block of Arrhythmogenic Disorders: Short QT Syndrome and Early Repolarization}

Andrea Mazzanti, MD (1), Katherine Underwood, BS (1), Dmitriy Nevelev, MD (1),

Shanna Kofman, MD (1), and Silvia G. Priori, MD, PhD (1), (2), (3)

(1) Molecular Cardiology, IRCCS ICS Maugeri, Pavia, Italy

(2) Department of Molecular Medicine, University of Pavia, Pavia, Italy

(3) Fundación Centro Nacional de Investigaciones Cardiovasculares, Madrid, Spain

This article has been accepted for publication and undergone full peer review but has not been through the copyediting, typesetting, pagination and proofreading process, which may lead to differences between this version and the Version of Record. Please cite this article as doi: $10.1111 /$ jce. 13265 . 


\section{Address for Correspondence:}

Silvia G. Priori, MD, PhD

Molecular Cardiology - IRCCS ICS Maugeri

Via Maugeri, 10 - 27100 Pavia, Italy

Telephone: +390382592040

Fax: +390382592059

E-mail: silvia.priori@icsmaugeri.it

Disclosures: None

\section{$\underline{\text { Abstract }}$}

Short QT Syndrome (SQTS) is a one of the rarest inheritable cardiac channelopathy, characterized by an accelerated cardiac repolarization, which is also the substrate for the development of lifethreatening ventricular arrhythmias. Up to this date, fewer than 200 SQTS cases have been reported in the literature worldwide. Patients with SQTS may experience a cardiac arrest as early as in the neonatal period or as late as 80 years old. The cumulative probability of experiencing a cardiac arrest by the fifth decade of life approaches $40 \%$, highlighting the importance of early recognition and management. SQTS is an autosomal dominant disease with five identified causative genes, including three that encode for potassium channels $(K C N H 2, K C N Q 1, K C N J 2)$ and two that encode for subunits of the L-type calcium channels (CACNA1C and CACNB2).

The term "early repolarization" (ER) has long been used to refer to a heterogeneous group of specific QRS-T junction patterns that are commonly found on the ECGs of young healthy subjects. In the last decade it has been suggested that in some individuals the presence of ER may be associated with an increased risk of sudden cardiac death, and thus the term "Early Repolarization Syndrome" (ERS) has progressively entered into use. Up to this point, however, whether ER constitutes a true primary arrhythmic disorder or whether it is simply a predisposing substrate that facilitates arrhythmias in the presence of other triggers remains an unresolved issue. 
In this review paper, we aim to integrate the current literature on SQTS and ERS. For each we will describe the key steps that first led to the identification of the syndrome before moving into a discussion of our current understanding of each entity, including the epidemiology, genetics, diagnosis, clinical manifestations, and management.

Keywords: Short QT Syndrome, Early Repolarization, Sudden Cardiac Death.

\section{$\underline{\text { Introduction }}$}

Advancements in genetic technologies and an expanding research focus on cardiac channelopathies have promoted an increased understanding of a variety of arrhythmogenic disorders. Recent investigations have led to the emergence of two new entities originally characterized by specific patterns on electrocardiogram (ECG): Short QT Syndrome (SQTS) and Early Repolarization Syndrome (ERS).

Currently, there exists a clear clinical definition for SQTS, although much remains unclear regarding the genetic background, risk stratification, and therapeutic options behind the condition. In contrast, as a scientific community we are still working to understand and define ERS as a clinical entity. Studying both of these syndromes has proven to be challenging, particularly given the lack of consensus terminology and the small population of identified affected patients, but significant developments have been made.

In this review paper, we aim to integrate the current literature on SQTS and ERS, the two newest arrhythmogenic disorders. For each we will describe the key steps that first led to the identification of the syndrome before moving into a discussion of our current understanding of each entity, including the epidemiology, genetics, diagnosis, clinical manifestations, and management.

\section{Short QT Syndrome}

\section{Introduction}

SQTS is a rare inheritable cardiac channelopathy, characterized by an accelerated cardiac repolarization, which is also responsible for the development of life-threatening ventricular arrhythmias. 


\section{Historical Background}

Prior to the 1990s, the discussion regarding QT interval was predominantly focused on its pathologic prolongation; a shortened QT interval, if noted at all, was viewed as a benign finding. Early suggestions of a possible correlation between short QT interval and an increased risk of ventricular arrhythmias were reported in 1986 by O'Rourke et al. ${ }^{1}$ in a study of arterial hemodynamics in kangaroos, who are known to have markedly short QT intervals and high rates of sudden cardiac death (SCD). The group observed that during left ventricular catheterization, 10 of the 14 kangaroos studied developed ventricular fibrillation (VF) upon contact of the catheter tip with endocardial tissue. The authors postulated that the short QT interval might be implicated in the high frequency of sudden death noted in these animals. Several years later, the mechanical inducibility of VF would again be observed during the evaluation of patients with SQTS. ${ }^{2}$

The pathogenicity of shortened QT intervals in humans was initially postulated in 1993 when Algra et al. ${ }^{3}$ investigated the correlation between the duration of QT interval assessed by 24-hour ECG and the 2 -year risk of sudden death in 6,693 consecutive patients. This seminal study concluded that a mean corrected QT interval (QTc) under $400 \mathrm{~ms}$ was associated with a 2.4-fold (95\% CI 1.4 to 4.3) increased risk of sudden death, a risk equivalent to that of having a QTc greater than $440 \mathrm{~ms}$ (i.e., a prolonged QT interval) in the same population.

Less than a decade later, the first case of SCD in the setting of a short QTc was documented, when Gussak et al. ${ }^{4}$ reported a 37-year-old woman who passed away suddenly 2 days after presenting with syncope and a QTc of $300 \mathrm{~ms}$. In the same paper the Authors provided also support for the heritable nature of a shortened QT interval, reporting a three-generations family with four members showing shortened QTc intervals, one of which had atrial fibrillation requiring electrical cardioversion. ${ }^{4}$

Finally, in 2003 Gaita et $\mathrm{al}^{2}$ conclusively defined SQTS, reporting on two unrelated families with extensive histories of SCD and uniformly shortened QT intervals (QTc under $300 \mathrm{~ms}$ ).

Since then, a significant amount of literature ${ }^{5,6}$ has contributed to our collective understanding of the epidemiology, pathophysiology, genetics, diagnosis, and management of patients with SQTS.

\section{Epidemiology}

SQTS is regarded as an extremely rare disease and, to date, fewer than 200 confirmed cases have been addressed in the literature worldwide. 
Even though it can be expected that with growing awareness an increasing number of cases will be disclosed, epidemiological data confirm that an "abnormally" short QT interval is not a frequent finding. ${ }^{7}$

The reports ${ }^{8-10}$ addressing the prevalence of short QT intervals have varied in the definition used to identify the lower limits of normality, with thresholds varying between 300 and 360 ms. Studies on healthy populations calculate the prevalence of QTc intervals under $360 \mathrm{~ms}$ and under $340 \mathrm{~ms}$ to be far less than $2 \%$ and $0.5 \%$, respectively. ${ }^{11}$ Unsurprisingly, studies assessing QTe values under $300 \mathrm{~ms}$ observe an almost undetectable prevalence. Reinig et al. ${ }^{12}$ in 2007 were unable to validate any QTc under $300 \mathrm{~ms}$ in 106,432 American patients, and a more recent evaluation of 1.7 million American patients only identified 45 cases under this value (prevalence of $0.003 \%$ ). ${ }^{13}$

One of the possible explanations for the rarity of individuals with short QT intervals in the general population is that the majority of studies focused on an adult population. Since SQTS patients may experience fatal arrhythmias in the early phases of life, screening of adults would fail to identify them, thereby leading to an underestimation of both the frequency and lethality of SQTS.

\section{Genetic Background}

SQTS is an autosomal dominant disease with five identified causative genes, including three that encode for potassium channels $\left(K C N H 2^{14}, K C N Q 1^{15}, K C N J 2^{16}\right)$ and two that encode for subunits of the L-type calcium channels (CACNAIC and $C A C N B 2^{17}$ ) (Figure 1). A sixth gene, coding for the delta subunit of the L-type calcium channe $1^{18}$ was reported as causative for SQTS in one family, but without a clear segregation pattern, the association with SQTS of this gene needs to be evaluated further.

Of note, the overall yield of genetic screening in SQTS patients is still extremely low (about $15 \%$ in our experience ${ }^{6}$ ), with none of the identified genes affecting more than 5\% of the known SQTS population. ${ }^{6,19}$ This suggests that the genetic heterogeneity of SQTS is wide and it should be expected that further causative genes will be identified.

Interestingly, the same genes involved in the pathogenesis of SQTS are also associated with Long QT Syndrome (LQTS) and Brugada Syndrome (BrS). The three implicated potassium channel genes are respectively affected in LQT2, LQT1, and LQT7. However, while in LQTS the causative defects cause loss-of-function mutations, in SQTS they induce much rarer gain-of-function mutations, increasing potassium current conduction and thereby shortening the duration of the ventricular action potential. 
Specifically, the mutations harbored in genes coding for the potassium channels (SQT1-3) share a common biophysical consequence, leading to increased repolarizing currents during the early portion of the plateau phase. In this phase of the action potential, the net repolarizing current is physiologically absent. The alterations of the gating properties of the potassium channels caused by SQTS-related variants result in an increased efflux of potassium ions during the plateau phase. This globally accelerates the cardiac repolarization and results in a remarkable and inhomogeneous shortening of the ventricular action potential duration, which represents the mechanism underlying arrhythmic susceptibility and sudden death risk.

In contrast, mutations harbored in genes coding for the subunits of the voltage-dependent calcium channels (SQT4-5) lead to decreased channel function. These variants are often associated with an overlapping appearance of SQTS and BrS. ${ }^{17}$

Due to the rarity of this disease, few studies exist that focus on the interplay between genotype and phenotype in SQTS. However, with the recent collection and availability of larger datasets of SQTS patients with a common genetic background, initial correlations are beginning to emerge, particularly for patients with $\mathrm{KCNH} 2$ mutations (SQT1).

SQT1 patients have been found to present with the shortest QTc values among all SQTS patients ${ }^{5}$, a later age of manifestation of the disease as compared to non-SQT1 patients ${ }^{20}$ and a striking response to the antiarrhythmic drug hydroquinidine, which is able to restore "normal" QTe values in them. ${ }^{5,21}$

Furthermore, both SQT1 and SQT2 patients have a high incidence of atrial arrhythmias, including atrial fibrillation and atrial flutter, which usually occur in the absence of structural heart disease and are possibly related to the very short atrial refractory periods that favor the generation and the sustenance of arrhythmias. ${ }^{22}$

\section{Diagnosis}

Population-based studies demonstrate that QTc values under $340 \mathrm{~ms}$ are exceedingly rare in the general population and the majority of identified probands with SQTS-related mutations exhibit QTc intervals up to $340 \mathrm{~ms} .^{6}$ Thus, according to current guidelines, patients with QTc $\leq 340 \mathrm{~ms}$ are diagnosed with SQTS even in the absence of symptoms. ${ }^{23}$

Similarly, population studies show that relatively few patients have QTc intervals shorter than $360 \mathrm{~ms}$ and these values should probably be regarded as "short." Consequently, SQTS should be considered in the presence of a QTc $<360 \mathrm{~ms}$ with one or more of the following: 
(a) history of documented ventricular tachycardia (VT) or VF in the absence of heart disease or reversible causes;

(b) family history of SQTS;

(c) family history of unexplained sudden death at age $\leq 40$; or

(d) a confirmed pathogenic mutation. ${ }^{23}$

As with QT prolongation, the first step in clarifying the diagnosis among patients with a suspected short QT is performing repeat ECGs to further study the QT duration and T-wave morphology at different heart rates, since the Bazett formula may overcorrect the QTc when heart rate is under 60 bpm: Kobza et al. ${ }^{9}$ found that less than $5 \%$ of all young males had QTc $<360 \mathrm{~ms}$, but when accounting only for ECGs recorded during sinus bradycardia, the percentage rose to approximately $20 \%$.

Patients with SQTS show a characteristically reduced adaptation of the QT interval to changes in heart rate, which may aid in the diagnosis of uncertain cases. In other words, these patients have QTc intervals in the low-to-normal range at heart rates around $60 \mathrm{bpm}$ that fail to shorten adequately at faster heart rates. Recording ECGs with different QT intervals at different heart rates may help distinguish the common patient with innocent QTc shortening during bradycardia from the rare SQTS patient with a "flat" QTc/R-R relationship. To address this point, Giustetto et al. ${ }^{24}$ compared the QT interval behavior during exercise in a cohort of 20 SQTS patients and in an age- and sex-matched control group. In addition to shorter QT intervals both at rest and at peak exercise, the SQTS group exhibited an impaired adaptation of the QT interval to the increasing heart rate. In fact, the mean QT variation from baseline to peak exercise was only $48 \pm 14 \mathrm{~ms}$ in SQTS patients as compared to $120 \pm 20$ $m s$ in control group $(p<0.0001)$, although the change in heart rate was not significantly different in both groups.

\section{Clinical Manifestations}

Patients with SQTS may present as early as in the neonatal period or as late as 80 years old. ${ }^{6,25}$

Cardiac arrest was the initial presenting symptom in $28 \%$ of patients in a case series of 29 patients and $32 \%$ of patients in a case series of 53 patients $^{5,25}$. The cumulative risk of cardiac arrest by age 40 is greater than $40 \%{ }^{6}$, highlighting the importance of early recognition and management.

In contrast to LQTS but in analogy to BrS, SQTS patients show an increased arrhythmic risk at rest. ${ }^{6}$ Interestingly, the circumstances of cardiac arrest appear to be reproducible in patients with multiple events. ${ }^{6}$ 
Both male and female SQTS patients exhibit arrhythmias, but while women appear to be at risk during their entire lifespan, males show a higher risk between mid-adolescence to 40 years of age, suggesting a possible hormonal (e.g., androgen related) influence on arrhythmias. The correlation of testosterone with QTc shortening has been shown in several studies. ${ }^{26,27}$ Interestingly, a study ${ }^{27}$ of women with polycystic ovarian syndrome (a state of elevated androgen levels) found a correlation between high testosterone levels and shortened QTc but failed to demonstrate an increased arrhythmic risk.

Lastly, atrial arrhythmias, including atrial fibrillation or flutter, are characteristically seen in SQTS patients (particularly SQT1), often occurring at a young age and without an association with myocardial abnormalities.

\section{Risk Stratification}

Determining which patients with short QT intervals are at highest risk of cardiac events is paramount given the high arrhythmic burden that may characterize SQTS. Unfortunately, the clinical manifestations of SQTS are variable, even within the same family, and a risk stratification scheme for asymptomatic patients with SQTS is not yet available. Importantly, and in contrast with LQTS, a relationship between the degree of QT interval shortening and an increased susceptibility to arrhythmias has not been demonstrated, nor has there been any support for the use of genotype to assess cardiac risk. ${ }^{6}$

Importantly, no clinical predictors of risk have been identified in asymptomatic individuals. In fact, several studies have reported adults with QTc up to $320 \mathrm{~ms}$ who remained asymptomatic during their entire life. ${ }^{8,9,28}$

Gollob et al. ${ }^{29}$ proposed diagnostic criteria consisting of QT interval length, length of J-point to Tpeak interval, clinical history, family history, and genotype. This scoring system was modified with the removal of event history to be used for risk stratification. Initial analyses have proved successful in predicting rates of SCD in the pediatric population. ${ }^{30}$ However, a subsequent analysis ${ }^{6}$ of a new cohort of 62 patients diagnosed with SQTS showed that neither the score nor the length of the QT interval correlated with event rate. The only predictor of arrhythmias in this study population was history of a previous cardiac arrest.

\section{Management}


SQTS patients who survived an episode of cardiac arrest or have documented spontaneous episodes of sustained VT/VF are candidates for an implantable cardioverter defibrillator (ICD), as the lifetime risk of recurrence has been shown to be as high as $60 \%{ }^{6}$

In patients with syncope of unknown origin, when there are not specific indications for the implant of an ICD, an implantable loop recorder may aid in correlating symptoms with alterations in cardiac rhythms as well as detecting asymptomatic arrhythmias.

Similarly, there are no data to support ICD implantation in asymptomatic SQTS patients and therefore management should be tailored to each individual.

Several pharmacological approaches have been also attempted in patients with SQTS, all aiming to prolong the duration of ventricular repolarization toward normal values.

Gaita et al. first evaluated several antiarrhythmic drugs (flecainide, sotalol, ibutilide, and hydroquinidine) in the first two SQTS families described who carried the Asn588Lys mutation in the $K C N H 2$ gene $^{31}$ and found that hydroquinidine (HQ) was the only agent able to provoke a significant prolongation of the QT interval (from $290 \pm 12 \mathrm{~ms}$ to $405 \pm 26 \mathrm{~ms}$ ), lengthen the ventricular effective refractory period above $200 \mathrm{~ms}$ and abolish the inducibility of ventricular arrhythmias during programmed electrical stimulation. The greater efficacy of HQ would later be explained by Wolpert et al., who found that the Asn588Lys mutation induced a 5.8-fold decrease in sensitivity of the mutant IKr potassium channel to HQ, in contrast to the 20 -fold decrease in the effect of sotalol. ${ }^{21}$ In 2011 Giustetto et al. reported on the long-term antiarrhythmic efficacy of HQ on all SQTS subtypes, despite the fact that patients without the $\mathrm{KNCNH} 2$ mutation exhibited a reduced and less homogenous lengthening of the QTc. ${ }^{5}$

Current guidelines recommend the consideration of HQ in patients who decline or have contraindications to ICD implantation and in asymptomatic patients with a diagnosis of SQTS and a family history of SCD. ${ }^{32}$ The former setting is especially useful in infants and pediatric patients, who have not yet reached an adequate age to implant an ICD. Furthermore, HQ can also be considered as an adjunctive therapy to prevent appropriate discharges in patients with ICDs and recurrent shocks.

The use of other antiarrhythmic drugs (including sotalol, propafenone, flecainide, disopyramide, amiodarone, vernakalant, and ranolazine) has also been suggested, but the experience in humans is limited at this time and therefore their use in clinical practice needs to be evaluated on a patient specific basis. ${ }^{33-38}$

\section{Early Repolarization}




\section{Initial Understanding of Early Repolarization and Sudden Cardiac Death}

\section{Introduction}

The term "early repolarization" (ER) has long been used to refer to a heterogeneous group of specific QRS-T junction patterns that are commonly found on the ECGs of young healthy subjects. In the last decade it has been suggested that in some individuals the presence of ER may be associated with an increased risk of VF, and thus the term "Early Repolarization Syndrome" (ERS) has progressively entered into use. Up to this point, however, whether ER constitutes a true primary arrhythmic disorder or whether it is simply a predisposing substrate that facilitates arrhythmias in the presence of other triggers remains an unresolved issue.

\section{Historical Background}

"Early repolarization" was first coined almost 70 years ago in reference to the ascending elevation of the QRS-T junction (also known as the "J-point") that was frequently observed in young healthy individuals. For over 60 years after the first description by Shipley and Hallaran in $1936^{39}$, this ECG finding was considered a benign phenomenon; in fact, it was also referred to as "juvenile ST-pattern" or "normal RS-T-segment elevation variant" to specifically distinguish it from the pathological STsegment elevation that is typical of acute coronary syndromes. ${ }^{39,40}$

Independent of this first phenomenon, the term "J-wave" (or Osborn wave) has been introduced to describe a low-frequency deflection that is morphologically similar to a P-wave but appears at the end of the QRS complex in the ECGs of severely hypothermic patients. In 1953, Osborn first associated this "current of injury" (from which the "J" in J-wave originates) with the onset of spontaneous VF during hypothermia. ${ }^{41}$

Since then, the term "ER" has been ambiguously used to describe either of these ECG signs, ${ }^{42,43}$ perhaps due to the confusing inclusion of a "J" in both terms. Although these findings can theoretically coexist in some individuals, they should be considered separately. ${ }^{44}$ The isolated J-point elevation is a frequent and very likely benign finding, whereas the presence of even a several millimeter long J-wave is an extremely rare and potentially ominous sign (Figure 2 ). ${ }^{44}$

\section{Epidemiology}

In the last 30 years, a heterogeneously defined ER pattern has been reported as a frequent finding in survivors of idiopathic VF (IVF). Therefore, the conviction has arisen that, similar to other arrhythmogenic conditions, ERS may be a cause of SCD in young individuals.

In 1984, Otto et al. ${ }^{45}$ first reported the presence of ER in three young male Southeast Asian refugees with IVF. Over the following decades, several other case-reports reinforced the association of ER with spontaneous VF. ${ }^{46-51}$

In 2008, a landmark study by Haissaguerre et al.$^{52}$ showed an increased presence of ER in the ECGs of malignant ventricular arrhythmia survivors, as compared to matched controls (31\% v. $5 \%$,

This article is protected by copyright. All rights reserved. 
$\mathrm{p}<0.005$ ). Nam et al. reinforced this finding in their correspondence ${ }^{53}$, citing that $60 \%$ of their IVF cohort $(n=15)$ exhibited ER on ECGs, versus $3.3 \%$ of control subjects $(n=1395)$.

More recently, Siebermair et al. ${ }^{54}$ investigated the correlation between ER and the propensity to develop life-threatening ventricular arrhythmias, identifying ER as the only predictor of arrhythmia recurrence in a cohort of 35 IVF survivors followed for 9 years (hazard ratio 3.9, 95\% CI 1.4-11.0; $\mathrm{P}=0.01)$.

In all of the aforementioned works, the definition of ER included the "elevation of the J-point, (presenting either as) QRS notching or slurring (J-wave)", supporting the original idea by Osborn that is the presence of a J-wave that increases the risk of VF. Nam et al. ${ }^{53}$ reinforced this concept, stating that a "transient accentuation of J-waves across the precordial and limb leads (was observed) before the development of electrical storms".

Along the same line, in 2013 Aizawa et al. ${ }^{55}$ performed a case study on 91 survivors of IVF without structural heart disease or known electrical disease and found that the presence of J-waves was observed in $93 \%$ of patients with history of arrhythmic storms as compared to $36 \%$ of those without storms $(\mathrm{p}<0.0001)$.

Since data from IVF cohorts could not be immediately translated to healthy subjects, large community-based trials have been conducted to test the association of ER with SCD on a population basis.

Tikkanen et al. ${ }^{56}$ in 2008 first reported an increased incidence of arrhythmic death associated with the presence of ER (relative risk 2.92 adjusted relative risk, 2.92; 95\% CI, 1.45 - 5.89; $\mathrm{P}=0.01$ ) in a cohort of 10,864 Finnish, middle-aged individuals with a prolonged follow-up of $30 \pm 11$ years. Also in this case the definition used included the presence of a J-wave.

Despite large studies demonstrating an association, there remains controversy. For instance, as part of the Atherosclerosis Risk in Communities (ARIC) study, Olson et al. evaluated the ECGs of 15,141 middle-aged subjects for presence of ER in any lead. After adjustment for possible confounders including demographic, clinical, lifestyle, and laboratory variables, ER was not significantly related to SCD (adjusted hazard ratio 1.23, 95\% CI 0.87-1.75). Interestingly, the definition of ER used by Olson et al. included only J-point elevation. ${ }^{42}$

In an attempt to summarize the large amount of data published since the first reports, Cheng et al. ${ }^{43}$ recently conducted a meta-analysis of 16 studies and 334,524 subjects to examine the link between ER and the risk of SCD. The work is methodologically interesting, as it included not only case-control studies, but also four cohorts that selected SCD as the endpoint of interest, for a total of 39,587 patients. Based on these data, the overall average prevalence of ER in the general population was estimated at 6.7\% (95\% confidence interval, CI, 2.5-17.7). Furthermore, it was calculated that ER is associated with an absolute risk increase of 140 additional SCD per 100,000 person-years (95\% CI 
130-149) and is therefore responsible for 7.3\% of SCD in the general population (95\% CI 1.9-15.2). As expected, the meta-analysis confirmed that case-control studies showed higher risk estimates than prospective and retrospective cohort studies (pooled odds ratio from case-control studies $4.25,95 \% \mathrm{CI}$ 1.84-9.81 vs. relative risk from cohort studies $1.33,95 \%$ CI 1.13-1.57, $\mathrm{P}=0.005)$. Nonetheless, the clinical significance of ER was also confirmed in cohort studies and, globally, subjects with ER were found to have twice the risk of SCD as compared to those without ER (relative risk 2.18; 95\% CI $1.29-3.68)$.

\section{Is there enough evidence to consider ER an "arrhythmogenic syndrome"?}

Although the link between ER and SCD appears convincing, a causal relation of the first on the second has not yet been demonstrated. Several points have to first be clarified to determine whether ER qualifies as an independent arrhythmogenic syndrome.

- First, there is considerable discrepancy in the prevalence of ER reported across several studies, ranging from $2 \%$ to $31 \%$ in population studies and reaching up to $90 \%$ in athletes. ${ }^{57}$, ${ }^{58}$ This variation highlights that misdiagnosis of ER is a true limiting factor in our ability to understand this condition and which forms are most dangerous. It has been stated that the prevalence of ER varies among ethnicities, genders and ages, but these discrepancies more likely reflect methodological issues than true variance among studied populations. As an example, in 2003 Klatsky et al. ${ }^{59}$ published the results of a longitudinal ECG study involving more than 73,000 individuals. The prevalence of ER was reported to be $0.9 \%$ when the ECG analysis was "not specific;" however, a secondary analysis performed on a subgroup of 2,234 ECGs from the same population that was specifically aimed to detect the presence of ER found a prevalence of $29 \%$.

- Second, there are ethnic-related differences in the risk of SCD associated with ER. In Asians and Caucasians, the presence of ER translated to an increased risk of SCD (relative risk 2.01, 95\% CI 1.3-3.1 and 1.5, 95\% CI 1.08-2.07, respectively), but not among African Americans (relative risk $0.82,95 \%$ CI $0.52-1.3$ ) despite a higher prevalence. ${ }^{43,60}$ These data raise the possibility that other factors, beyond the presence of ER, may influence the susceptibility to SCD at the population level.

- Lastly, there is the potential existence of confounding variables. Observational studies are not substantial enough to establish a causal link between the presence of ER on ECG and the risk of SCD. Although ER has been associated with an increased risk of SCD independent of conventional cardiovascular risk factors (such as body mass index, cholesterol, diabetes, hypertension, smoking, heart rate, history of coronary artery disease), correction for other 
possible markers of an increased arrhythmic risk (such as QT interval duration or the presence of left ventricular hypertrophy) have been rarely tested ${ }^{56}$, if ever. Furthermore, in large population-based trials, ${ }^{56}$ survival curves of patients with and without ER diverge in middle age subjects, whereas the majority of SCD related to inherited arrhythmogenic disorders occur at younger ages. ${ }^{6,61-63}$

To demonstrate the difficulty in establishing a causal link between ER and SCD in 2011, Derval et $\mathrm{al}^{64}$ utilized preliminary CASPER data to shed light on the prevalence of ER in a cohort of 100 patients with unexplained cardiac arrest and normal coronary arteries. Significant ER was present in $19 \%$ of all cardiac arrest survivors, but there was no difference in ER prevalence between patients eventually found to have a primary diagnosis (for instance, $\mathrm{BrS}$ ) as compared to those with confirmed IVF $(\mathrm{P}=0.24)$. It seems therefore that $\mathrm{ER}$ represents more a risk factor for life-threatening arrhythmias than an arrhythmogenic syndrome on its own.

\section{ER as a risk modifier in patients with acquired and congenital cardiovascular diseases}

The late burden of mortality associated with ER, together with the large amount of heterogeneity observed in the results of studies, strengthens the view of ER acting as a proarrhythmic substrate with additional external factors precipitating the final onset of life-threatening arrhythmias at the population level.

In chronic coronary heart disease patients, the prevalence of ER in inferior leads was about threefold higher among patients receiving appropriate ICD therapy for VT/VF than in those without ventricular arrhythmias, independent of ejection fraction $(23 \%$ vs. $8 \% \mathrm{P}=0.03) .{ }^{65}$ The same observation has been made in the context of acute myocardial infarction: Zhang et al. ${ }^{66}$ conducted a meta-analysis of 7 studies with a total of 1,565 patients (299 with ER and 1,266 without ER) demonstrating that patients with ER showed an increased risk of VF, as compared with age- and sexmatched control subjects (odds ratio 3.75, 95\% CI: 2.62-5.37, $\mathrm{P}<0.00001$ ).

Additionally, in inherited arrhythmogenic syndromes the presence of ER has been found to portend an increased risk of life-threatening arrhythmias.

In patients with BrS, Kamakura et al. ${ }^{67}$ found that VF mostly recurs in patients with ER associated with the presence of a spontaneous type 1 Brugada pattern in any right precordial lead, including the upper intercostal leads. Georgopoulos et al. ${ }^{68}$ conducted a meta-analysis of five studies comprising a total of 1,375 patients with BrS and found an ER pattern in 12.8\% of cases. During follow-up (45-93 months), 143 patients (10.4\%) suffered an arrhythmic event. Overall, BrS patients with ER pattern displayed an increased risk of arrhythmic events compared to patients without ER (odds ratio 3.29, 95\% CI: 2.06-5.26, $\mathrm{P}<0.00001)$. 
A special link between ER and SQTS has been postulated to exist since the observation by Haissaguerre et al. ${ }^{52}$ who reported that, among patients with IVF, the QT interval was shorter in patients with ER than in those without. Subsequently, Watanabe et al. ${ }^{69}$ showed that ER had a prevalence of $88 \%$ in a cohort of SQTS patients and as well as that ER was associated with arrhythmic events in his cohort compared to both a control cohort of asymptomatic short QT patients (odds ratio 5.64, 95\% CI 1.97-16.15, $\mathrm{P}=0.001$ ) and to a cohort of subjects with normal QT (odds ratio $16.58,95 \%$ CI 7.2-38.21, $\mathrm{P}<0.001)$.

These observations motivated us to assess the prevalence of ER as defined by MacFarlane et al. ${ }^{70}$ in our cohort of 73 SQTS patients, ${ }^{6}$ and we found that ER was present in $29 \%$ of our cases. This prevalence was comparable with that observed in 146 age- and sex-matched controls, who demonstrated a prevalence of $27 \%(\mathrm{P}=0.83)$. Furthermore, this $\mathrm{ECG}$ pattern was not associated with an increased risk of experiencing life-threatening arrhythmias in our SQTS cohort, thus confirming that risk stratification in SQTS remains challenging (unpublished data).

\section{Modern Approach to Early Repolarization: Focus on the J-Wave}

\section{Toward a Shared Definition for Early Repolarization}

The lack of a shared definition is currently the main limitation to understanding ER. The controversy of the benign or malignant nature of ER can be attributed to the erroneously interchangeable definitions, which include either the presence of a J-wave, a J-point elevation, or both.

Since the work by Haissaguerre et al. ${ }^{52}$ was published in 2008, the definition of ER has gradually shifted away from the traditional focus on ST-segment elevation towards the J-wave, which can manifest as QRS notching or slurring.

In 2015 a unified definition of the ER pattern was proposed for the first time, which took into account the concept of ER as a potential arrhythmogenic marker. ${ }^{70}$

According to the expert consensus, ${ }^{70}$ the "modern" definition of ER includes both:

(1) a J-wave: a notch and/or slur of the end-QRS segment (i.e., occurring on the final $50 \%$ of the downslope of an R-wave), lying entirely above the baseline; and

(2) a J-point elevation of $\geq 0.1 \mathrm{mV}$ in two consecutive inferior and/or lateral leads (leads V1-V3 are excluded from the evaluation). The J-point corresponds to the peak of the notch or to the onset of the slur.

Importantly, all ST-segment elevations without notching and/or slurring of the QRS were removed from the definition, as well as those ECGs with QRS duration > $120 \mathrm{~ms}$.

Furthermore, at present the term "Early Repolarization Syndrome" (ERS) should be reserved to patients who display ER in the inferior and/or lateral leads presenting with aborted cardiac arrest, documented VF, or polymorphic VT. ${ }^{71}$ 
A multiparametric diagnostic score system for ERS, referred to as the Proposed Shanghai ERS Score, has been recently proposed, ${ }^{71}$ but it will need to undergo validation in future studies before entering in the clinical practice.

\section{Understanding the pathophysiology of Early Repolarization}

Not only has the definition of ER varied in the literature, but the pathophysiology of ER has also engendered controversy. Two hypotheses exist for the origin of the J-wave on the ECG.

The first hypothesis proposes that the notch at the end of QRS is a depolarization abnormality dependent on a delay in intraventricular conduction. In a study of 22 IVF cases, patients with ER also showed a significantly greater incidence of late potentials, which is a marker of depolarization, than those without ER ( $86 \%$ vs. $27 \%, \mathrm{P}=0.02)$. ${ }^{72}$ Since repolarization markers did not differ between the groups, the investigators concluded that ER may be more closely associated with a depolarization abnormality. However, a larger study of 206 subjects with idiopathic VF showed a similar prevalence of late potentials in patients with ER on their ECG as compared to a control group with no ER pattern $(11 \% \text { vs. } 13 \%, \mathrm{P}=0.84)^{52}$, suggesting that $\mathrm{ER}$ is not a depolarization phenomenon. Furthermore, it is important to remember that delayed conduction is usually exaggerated at faster heart rates, whereas the J-wave of ER is typically increased during bradycardia and mitigated at faster rates. ${ }^{71}$ According to an alternate hypothesis, ER would be a marker of increased transmural heterogeneity of ventricular repolarization, which might increase the vulnerability to VF. ${ }^{73}$ Accordingly, the inscription of the J-wave on the ECG would be secondary to the presence of repolarizing gradients across different layers of the left ventricular wall. These might be the result of increased outward potassium currents (mediated by Ito, IK-ATP and IK-Ach channels) or decreased inward depolarizing currents (mediated by INa or ICaL channels). ${ }^{71}$

Today, the latter theory is the most accredited and also provides support for the mechanisms involved in the association between ER and mortality. The transmural heterogeneous distribution of repolarizing forces, in fact, would create a prominent Ito-mediated action potential notch in the epicardium, but not the endocardium. Further accentuation of Ito current, for example during an episode of myocardial ischemia, would lead to a disproportionate shortening of the epicardial action potential thus facilitating the generation of phase 2 reentries and VF. ${ }^{71}$ According to this view, the ER pattern might serve as a substrate that can increase sudden death risk in the presence of triggers, such as Purkinje extrasystoles with a short coupling interval, which account for the majority of VF onset in younger individuals, or myocardial ischemia, which commonly precipitates episodes of VF in adult patients with coronary artery disease.

\section{Delineating the identikit of malignant ER}

As the scientific community has been working towards a consensus on a unifying diagnosis, there have also been efforts to identify ECG characteristics that may help us distinguish benign ER from its 
malignant counterpart. Various features of the J-wave, ST-segment, and T-wave have all been highlighted as ECG findings that portend an increased arrhythmogenic risk.

A large research focus has been placed on identifying key attributes of the J-wave that may signal a more malignant form of ER. As one example, the notching morphology is associated with up to a four-fold increased risk of SCD when compared to the slurring morphology (odds ratio 3.85, $\mathrm{P}=0.002){ }^{66}$

Separately, the risk of experiencing SCD among subjects with a J-point elevation of more than $\mathbf{0 . 2}$ $\mathbf{m V}$ in the inferior leads was 3 times as high as the risk of SCD among those who did not demonstrate ER (relative risk $2.92,95 \%$ CI $1.45-5.89, \mathrm{P}=0.003$ ). ${ }^{43}$

With respect to the duration of the $\mathbf{J}$-wave, a literature review by Cristoforetti et al. suggested that a duration $>\mathbf{6 0} \mathbf{~ m s}$ is a marker of increased risk of VF $(\mathrm{P}<0.001) .{ }^{74}$ Additional studies have sought to investigate if the localization of the J-wave is of any importance and have concluded that global $\mathbf{J}$ waves in both inferior and lateral leads are associated with the highest risk of arrhythmic events (odds ratio 4.87, 95\% CI: 2.64 to 9.01, $\mathrm{P}<0.00001$ ) ${ }^{68}$ followed by J waves in inferior leads (hazard ratio $3,95 \%$ CI $1.45-5.89 \mathrm{P}<0.01) .{ }^{56}$

Other ECG findings that have been investigated include the ST-segment and the T-wave. An STsegment that is horizontal or down-sloping portends a higher risk in both the general population and in IVF patients (relative risk 2.03; 95\% CI 1.10- 3.74; $\mathrm{P}=0.02$ ) ${ }^{43}$. To contrast this, the ST-segment in the J-point elevation that is often seen in healthy young adults is typically ascending.

Finally, a recent paper found that there is higher prevalence of low-voltage $\mathbf{T}$ waves among patients with ER and VF when compared to asymptomatic patients with ER (29\% vs. 3\%, P 0.001). ${ }^{75}$

All of the above ECG parameters have been demonstrated to be associated with arrhythmia risk in separate studies; however, the absolute risk conferred by each variant is small and, in isolation, these ECG markers are of limited value as risk stratification tools in clinical practice.

\section{A Genetic Background for ER}

Several studies suggest that the finding of an ER pattern on ECGs is "familial". $76-78$

Due to the heterogeneity of its manifestations, it is conceivable that various genetic forms of ER may exist, ranging from complex polygenic variants to highly penetrant Mendelian forms. A study ${ }^{78}$ of 505 British families suggested a 2.5 times increased risk in offspring of subjects with ER (95\% CI 1.334.84, $\mathrm{P}=0.005$ ). Likewise, an analysis of the Framingham population showed a two-fold increase in risk. ${ }^{76}$ Recently Gourraud et al. ${ }^{79}$ identified four large families with apparently autosomal dominant transmission of ER and with several cases of early sudden death, but the genetic background of these families is not reported. To further complicate the subject, a large scale meta-analysis of genome-wide association studies involving over 14,500 individuals provides some opposing evidence and did not identify any common variants significantly associated with ER. ${ }^{73}$ 
Thus far, genetic variants in seven genes associated with ER have been identified. ${ }^{71}$

Two variants reported in ERS patients are KCNJ8 and $A B C C 9$, responsible for the pore-forming and ATP-sensing subunits of the IK-ATP channel, which have been shown to generate ER in canine ventricular wedge preparations. ${ }^{80,81}$ Additionally, loss-of-function variations in the $\alpha 1, \beta 2$, and $\alpha 2 \delta$ subunits of the cardiac L-type calcium channel (CACNA1C, CACNB2, CACNA2D1) and the $\alpha 1$ subunit of $\mathrm{Na}_{\mathrm{V}} 1.5$ and $\mathrm{Na}_{\mathrm{V}} 1.8(S C N 5 A, S C N 10 A)$ have been reported in patients with ER. ${ }^{82-84}$ Importantly, only a small number of these variants have been examined using functional expression studies and thus causality cannot be established unless clear segregation data exist. The lack of functional or biologic validation of mutation effects remains the most severe limitation of genetic test interpretation. ${ }^{71}$ Therefore, given the very limited understanding of the genetic basis of ER, genetic testing for the condition may have low sensitivity and specificity as well as a risk of discovering a genetic variant of unknown clinical significance. Genetic testing of ER cases is therefore restricted to the research field since it does not have clear clinical utility yet.

\section{Management of patients with $E R$}

The crux of the modern approach towards managing ER is to stratification by SCD risk.

According to current guidelines, survivors of an episode of VF with documentation of ER have a class I indication for the implant of an ICD. ${ }^{23}$

No guidelines exist for the treatment of patients with ER who have syncope or are asymptomatic. In particular, there are no indications for the implant of an ICD in these patients groups and treatment needs to be personalized for each individual.

For patients presenting with syncope, the circumstances of the syncopal event need to be carefully investigated. In the presence of syncope occurring without an alternative cause, an implantable loop recorder may be considered, particularly in patients with "high risk" ER and/or family history of SCD. The majority of patients with ER on ECG, however, are asymptomatic and likely do not require any intervention. In fact, until a more precise definition of "malignant" ER is reached, ER needs to be considered a normal variant from a population perspective, given its high overall frequency.

Furthermore, large epidemiological studies suggest that the risk of SCD associated with ER in the general population is low: data from Rosso et al. show that the finding of ER in a young adult would increase the probability of idiopathic VF from 1 in 30,000 to 1 in 10,000 individuals per year ${ }^{85}$. This risk is obviously too low to suggest any specific intervention.

Further prospective studies concentrating on the estimated prevalence of "high risk" ER and its correlation to outcome are necessary. 


\section{Conclusion}

In the last 20 years SQTS has emerged as a new inheritable arrhythmogenic syndrome. Several aspects of its pathophysiology and of the natural history of affected individuals have been clarified; furthermore, initial insights in genotype-phenotype correlations are emerging. Much more, however, needs to done, to better understand its heterogeneous genetic background, to learn how to risk stratify asymptomatic individuals for the risk of SCD and to find therapeutic strategies able to prevent arrhythmias. Progressing towards these goals will require identified patients to be referred to a shared registry and genetic testing of each case will be vital.

Early Repolarization has also emerged as a possible arrhythmogenic condition, after having been considered a physiological variant of a normal ECG for decades. This modern view of ER is related to the presence of a J-wave and, in order to gain a better understanding of its pathological role, the scientific community will need to progressively abandon the use of "ER" to refer to the ECG appearance of young and healthy individuals.

If we will not be able to reach a consensus on a shared definition for ER, the noise surrounding this term will remain so loud that the concept of ER as a potentially independent arrhythmogenic syndrome will gradually fade.

\section{Figure legends.}

Figure 1. Electrocardiographic Characteristics of Genotype-Positive SQTS families. Each row refers to a kindred. Columns from left to right show gene and mutation identified; ECG of probands; the family tree; QTc interval duration, as numbered in the family tree. In the pedigree column, affected subjects are indicated by the solid symbols, unaffected subjects by open symbols, and sudden death victims by the grey symbols. $+=$ mutation carrier; $-=$ mutation non-carrier; $\rightarrow=$ probands; $\square=$ male patients; $\mathrm{O}=$ female patients. $\mathrm{ECG}=$ electrocardiogram; $\mathrm{QTc}=$ corrected QT interval. Modified with permission from Mazzanti A. et al. Journal of the American College of Cardiology. 2014;63(13):1300-1308. 


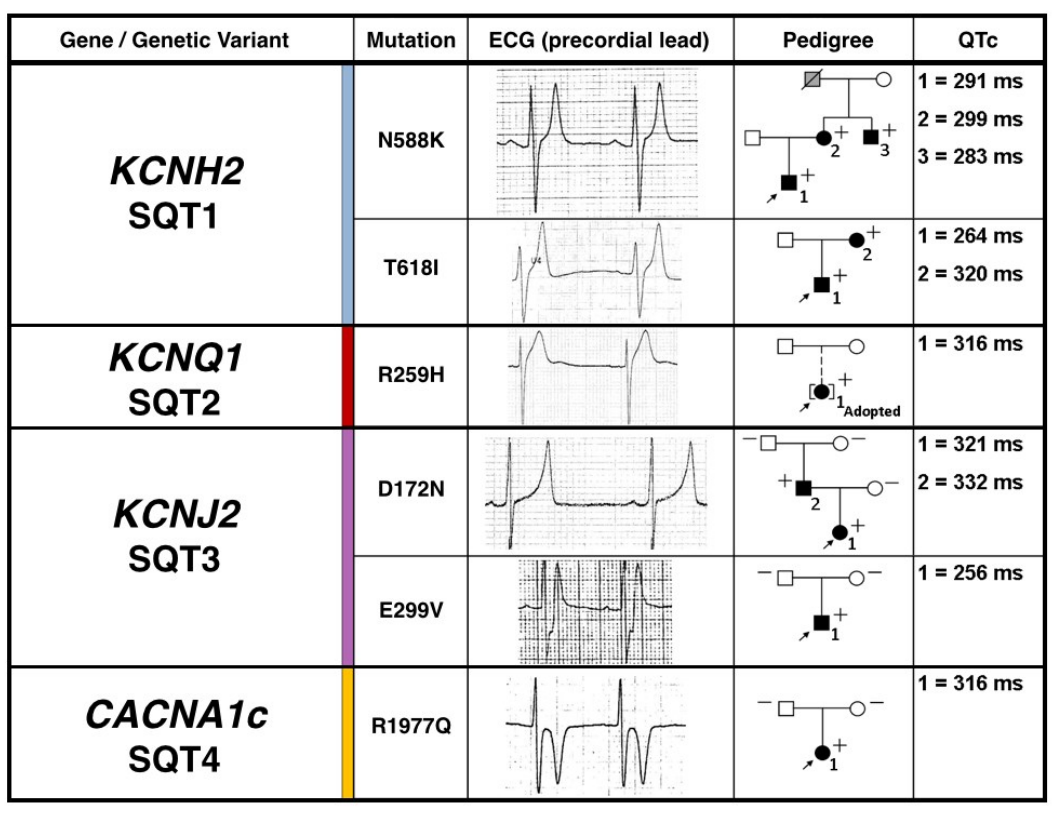

Figure 2. Differentiating isolated J-point elevation from Early Repolarization (ER). Panel A shows an example of isolated J-point elevation in a 25 year-old asymptomatic male athlete. Panels B and $\mathrm{C}$ show the two aspects of Early Repolarization pattern as proposed by MacFarlane et al. Panel B illustrates the end-QRS notching variant accompanied by, while panel C illustrates the slurring variant. When the angle between the initial downslope of the R-wave and the end-QRS inscription exceeds $10^{\circ}$, a slur is defined as present. The definitions are taken from MacFarlane et al. ((Journal of the American College of Cardiology. 2015;66(4):470-477).

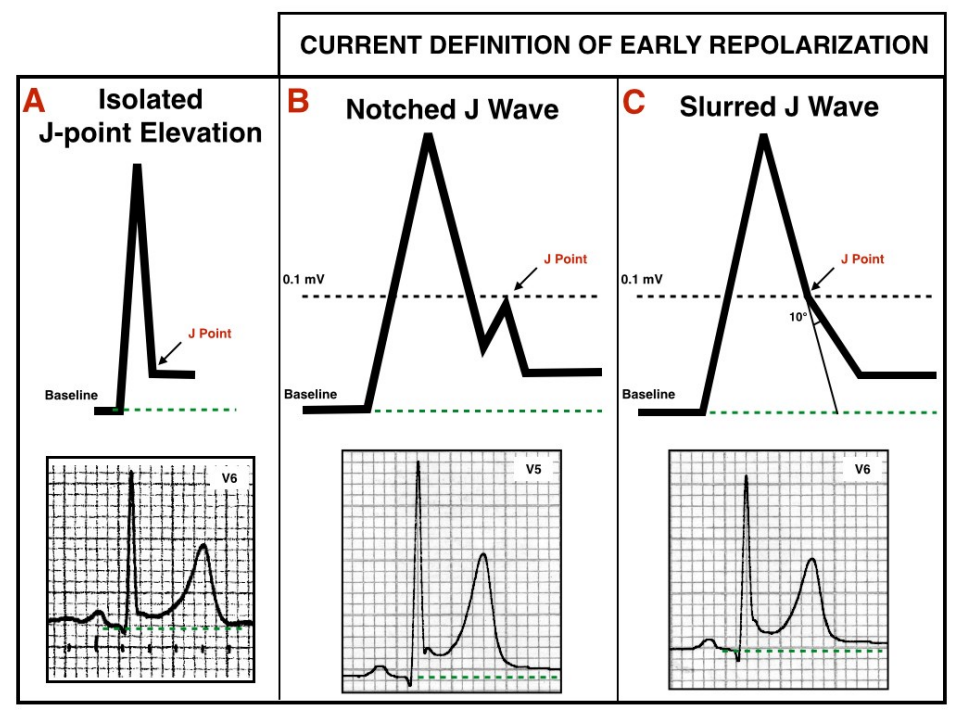




\section{Bibliography}

1. O'Rourke MF, Avolio AP and Nichols WW. The kangaroo as a model for the study of hypertrophic cardiomyopathy in man. Cardiovascular research. 1986;20:398-402.

2. Gaita F, Giustetto C, Bianchi F, Wolpert C, Schimpf R, Riccardi R, Grossi S, Richiardi E and Borggrefe M. Short QT Syndrome: a familial cause of sudden death. Circulation. 2003;108:96570.

3. Algra A, Tijssen JG, Roelandt JR, Pool J and Lubsen J. QT interval variables from 24 hour electrocardiography and the two year risk of sudden death. British heart journal. 1993;70:43-8.

4. Gussak I, Brugada P, Brugada J, Wright RS, Kopecky SL, Chaitman BR and Bjerregaard P. Idiopathic short QT interval: a new clinical syndrome? Cardiology. 2000;94:99-102.

5. Giustetto C, Schimpf R, Mazzanti A, Scrocco C, Maury P, Anttonen O, Probst V, Blanc JJ, Sbragia P, Dalmasso P, Borggrefe M and Gaita F. Long-term follow-up of patients with short QT syndrome. J Am Coll Cardiol. 2011;58:587-95.

6. Mazzanti A, Kanthan A, Monteforte N, Memmi M, Bloise R, Novelli V, Miceli C, O'Rourke S, Borio G, Zienciuk-Krajka A, Curcio A, Surducan AE, Colombo M, Napolitano C and Priori SG. Novel insight into the natural history of short QT syndrome. Journal of the American College of Cardiology. 2014;63:1300-8.

7. Priori SG, Napolitano C, Gasparini M, Pappone C, Della Bella P, Giordano U, Bloise R, Giustetto C, De Nardis R, Grillo M, Ronchetti E, Faggiano G and Nastoli J. Natural history of Brugada syndrome: insights for risk stratification and management. Circulation.

2002;105:1342-7.

8. Funada A, Hayashi K, Ino H, Fujino N, Uchiyama K, Sakata K, Masuta E, Sakamoto Y, Tsubokawa T and Yamagishi M. Assessment of QT intervals and prevalence of short QT syndrome in Japan. Clinical cardiology. 2008;31:270-4.

9. Kobza R, Roos M, Niggli B, Abacherli R, Lupi GA, Frey F, Schmid JJ and Erne P. Prevalence of long and short QT in a young population of 41,767 predominantly male Swiss conscripts. Heart rhythm. 2009;6:652-7.

10. Mason JW, Ramseth DJ, Chanter DO, Moon TE, Goodman DB and Mendzelevski B. Electrocardiographic reference ranges derived from 79,743 ambulatory subjects. Journal of electrocardiology. 2007;40:228-34.

11. Anttonen O, Junttila MJ, Rissanen H, Reunanen A, Viitasalo M and Huikuri HV. Prevalence and prognostic significance of short QT interval in a middle-aged Finnish population. Circulation. 2007;116:714-20.

12. Reinig MG and Engel TR. The shortage of short QT intervals. Chest. 2007;132:246-9. 
13. Iribarren C, Round AD, Peng JA, Lu M, Klatsky AL, Zaroff JG, Holve TJ, Prasad A and Stang P. Short QT in a cohort of 1.7 million persons: prevalence, correlates, and prognosis. Annals of noninvasive electrocardiology : the official journal of the International Society for Holter and Noninvasive Electrocardiology, Inc. 2014;19:490-500.

14. Brugada R, Hong K, Dumaine R, Cordeiro J, Gaita F, Borggrefe M, Menendez TM, Brugada J, Pollevick GD, Wolpert C, Burashnikov E, Matsuo K, Wu YS, Guerchicoff A, Bianchi F, Giustetto C, Schimpf R, Brugada P and Antzelevitch C. Sudden death associated with short-QT syndrome linked to mutations in HERG. Circulation. 2004;109:30-5.

15. Hong K, Bjerregaard P, Gussak I and Brugada R. Short QT syndrome and atrial fibrillation caused by mutation in KCNH2. J Cardiovasc Electrophysiol 2005;16:394-6.

16. Priori SG, Pandit SV, Rivolta I, Berenfeld O, Ronchetti E, Dhamoon A, Napolitano C, Anumonwo J, di Barletta MR, Gudapakkam S, Bosi G, Stramba-Badiale M and Jalife J. A novel form of short QT syndrome (SQT3) is caused by a mutation in the KCNJ2 gene. Circulation research. 2005;96:800-7.

17. Antzelevitch C, Pollevick GD, Cordeiro JM, Casis O, Sanguinetti MC, Aizawa Y, Guerchicoff A, Pfeiffer R, Oliva A, Wollnik B, Gelber P, Bonaros EP, Jr., Burashnikov E, Wu Y, Sargent JD, Schickel S, Oberheiden R, Bhatia A, Hsu LF, Haissaguerre M, Schimpf R, Borggrefe M and Wolpert C. Loss-of-function mutations in the cardiac calcium channel underlie a new clinical entity characterized by ST-segment elevation, short QT intervals, and sudden cardiac death.

Circulation. 2007;115:442-9.

18. Templin C, Ghadri JR, Rougier JS, Baumer A, Kaplan V, Albesa M, Sticht H, Rauch A, Puleo C, Hu D, Barajas-Martinez H, Antzelevitch C, Luscher TF, Abriel H and Duru F. Identification of a novel loss-of-function calcium channel gene mutation in short QT syndrome (SQTS6). European heart journal. 2011;32:1077-88.

19. Ackerman MJ, Priori SG, Willems S, Berul C, Brugada R, Calkins H, Camm AJ, Ellinor PT, Gollob M, Hamilton R, Hershberger RE, Judge DP, Le Marec H, McKenna WJ, Schulze-Bahr E, Semsarian C, Towbin JA, Watkins H, Wilde A, Wolpert C and Zipes DP. HRS/EHRA expert consensus statement on the state of genetic testing for the channelopathies and cardiomyopathies. Europace : European pacing, arrhythmias, and cardiac electrophysiology: journal of the working groups on cardiac pacing, arrhythmias, and cardiac cellular electrophysiology of the European Society of Cardiology. 2011;13:1077-109.

20. Harrell DT, Ashihara T, Ishikawa T, Tominaga I, Mazzanti A, Takahashi K, Oginosawa Y, Abe H, Maemura K, Sumitomo N, Uno K, Takano M, Priori SG and Makita N. Genotype-dependent differences in age of manifestation and arrhythmia complications in short QT syndrome. International journal of cardiology. 2015;190:393-402.

21. Wolpert C, Schimpf R, Giustetto C, Antzelevitch C, Cordeiro J, Dumaine R, Brugada R, Hong K, Bauersfeld U, Gaita F and Borggrefe M. Further insights into the effect of quinidine in short QT syndrome caused by a mutation in HERG. J Cardiovasc Electrophysiol. 2005;16:54-8. 
22. Nattel S. New ideas about atrial fibrillation 50 years on. Nature. 2002;415:219-26.

23. Priori SG, Blomstrom-Lundqvist C, Mazzanti A, Blom N, Borggrefe M, Camm JA, Elliott PM, Fitzsimons D, Hatala R, Hindricks G, Kirchhof P, Kjeldsen K, Kuck KH, Hernandez Madrid A, Nikolaou N, Norekval TM, Spaulding C and DJ VV. 2015 ESC guidelines for the management of patients with ventricular arrhythmias and the prevention of sudden cardiac death. European heart journal. 2015.

24. Giustetto C, Scrocco C, Schimpf R, Maury P, Mazzanti A, Levetto M, Anttonen O, Dalmasso P, Cerrato N, Gribaudo E, Wolpert C, Giachino D, Antzelevitch C, Borggrefe M and Gaita F. Usefulness of exercise test in the diagnosis of short QT syndrome. Europace : European pacing, arrhythmias, and cardiac electrophysiology : journal of the working groups on cardiac pacing, arrhythmias, and cardiac cellular electrophysiology of the European Society of Cardiology. 2015;17:628-34.

25. Giustetto C, Di Monte F, Wolpert C, Borggrefe M, Schimpf R, Sbragia P, Leone G, Maury P, Anttonen O, Haissaguerre M and Gaita F. Short QT syndrome: clinical findings and diagnostictherapeutic implications. European heart journal. 2006;27:2440-7.

26. Sedlak T, Shufelt C, Iribarren C and Merz CN. Sex hormones and the QT interval: a review. Journal of women's health. 2012;21:933-41.

27. Vrtovec B, Meden-Vrtovec H, Jensterle M and Radovancevic B. Testosterone-related shortening of QTc interval in women with polycystic ovary syndrome. Journal of endocrinological investigation. 2008;31:653-5.

28. Gallagher MM, Magliano G, Yap YG, Padula M, Morgia V, Postorino C, Di Liberato F, Leo R, Borzi M and Romeo F. Distribution and prognostic significance of QT intervals in the lowest half centile in 12,012 apparently healthy persons. The American journal of cardiology. 2006;98:9335 .

29. Gollob MH, Redpath CJ and Roberts JD. The short QT syndrome: proposed diagnostic criteria. Journal of the American College of Cardiology. 2011;57:802-12.

30. Villafane J, Atallah J, Gollob MH, Maury P, Wolpert C, Gebauer R, Watanabe H, Horie M, Anttonen O, Kannankeril P, Faulknier B, Bleiz J, Makiyama T, Shimizu W, Hamilton RM and Young ML. Long-term follow-up of a pediatric cohort with short QT syndrome. Journal of the American College of Cardiology. 2013;61:1183-91.

31. Gaita F, Giustetto C, Bianchi F, Schimpf R, Haissaguerre M, Calo L, Brugada R, Antzelevitch C, Borggrefe M and Wolpert C. Short QT syndrome: pharmacological treatment. J Am Coll Cardiol. 2004;43:1494-9.

32. Priori SG, Blomstrom-Lundqvist C, Mazzanti A, Blom N, Borggrefe M, Camm J, Elliott PM, Fitzsimons D, Hatala R, Hindricks G, Kirchhof P, Kjeldsen K, Kuck KH, Hernandez-Madrid A, Nikolaou N, Norekval TM, Spaulding C, Van Veldhuisen DJ, Task Force for the Management of Patients with Ventricular A and the Prevention of Sudden Cardiac Death of the European Society 
of C. 2015 ESC Guidelines for the management of patients with ventricular arrhythmias and the prevention of sudden cardiac death: The Task Force for the Management of Patients with Ventricular Arrhythmias and the Prevention of Sudden Cardiac Death of the European Society of Cardiology (ESC)Endorsed by: Association for European Paediatric and Congenital Cardiology (AEPC). Europace. 2015;17:1601-87.

33. McPate MJ, Duncan RS, Hancox JC and Witchel HJ. Pharmacology of the short QT syndrome N588K-hERG K+ channel mutation: differential impact on selected class I and class III antiarrhythmic drugs. Br J Pharmacol. 2008;155:957-66.

34. McPate MJ, Duncan RS, Witchel HJ and Hancox JC. Disopyramide is an effective inhibitor of mutant HERG K+ channels involved in variant 1 short QT syndrome. J Mol Cell Cardiol. 2006;41:563-6.

35. Milberg P, Tegelkamp R, Osada N, Schimpf R, Wolpert C, Breithardt G, Borggrefe M and Eckardt L. Reduction of dispersion of repolarization and prolongation of postrepolarization refractoriness explain the antiarrhythmic effects of quinidine in a model of short QT syndrome. $J$ Cardiovasc Electrophysiol. 2007;18:658-64.

36. Mizobuchi M, Enjoji Y, Yamamoto R, Ono T, Funatsu A, Kambayashi D, Kobayashi T and Nakamura S. Nifekalant and disopyramide in a patient with short QT syndrome: evaluation of pharmacological effects and electrophysiological properties. Pacing Clin Electrophysiol. 2008;31:1229-32.

37. Sun Y, Quan XQ, Fromme S, Cox RH, Zhang P, Zhang L, Guo D, Guo J, Patel C, Kowey PR and Yan GX. A novel mutation in the KCNH2 gene associated with short QT syndrome.J Mol Cell Cardiol. 2011;50:433-41.

38. Frommeyer G, Ellermann C, Dechering DG, Kochhauser S, Bogeholz N, Guner F, Leitz P, Pott C and Eckardt L. Ranolazine and Vernakalant Prevent Ventricular Arrhythmias in an Experimental Whole-Heart Model of Short QT Syndrome. J Cardiovasc Electrophysiol. 2016;27:1214-1219.

39. Shipley AM. Suppurative Pericarditis: Late Results and Methods of Drainage. Annals of surgery. 1936;103:698-705.

40. Wasserburger RH and Alt WJ. The normal RS-T segment elevation variant. The American journal of cardiology. 1961;8:184-92.

41. Osborn JJ. Experimental hypothermia; respiratory and blood $\mathrm{pH}$ changes in relation to cardiac function. The American journal of physiology. 1953;175:389-98.

42. Olson KA, Viera AJ, Soliman EZ, Crow RS and Rosamond WD. Long-term prognosis associated with J-point elevation in a large middle-aged biracial cohort: the ARIC study. European heart journal. 2011;32:3098-106.

43. Cheng YJ, Lin XX, Ji CC, Chen XM, Liu LJ, Tang K and Wu SH. Role of Early Repolarization Pattern in Increasing Risk of Death. Journal of the American Heart Association. 2016;5. 
44. Surawicz B and Macfarlane PW. Inappropriate and confusing electrocardiographic terms: J-wave syndromes and early repolarization. Journal of the American College of Cardiology. 2011;57:1584-6.

45. Otto CM, Tauxe RV, Cobb LA, Greene HL, Gross BW, Werner JA, Burroughs RW, Samson WE, Weaver WD and Trobaugh GB. Ventricular fibrillation causes sudden death in Southeast Asian immigrants. Annals of internal medicine. 1984;101:45-7.

46. Takagi M, Aihara N, Takaki H, Taguchi A, Shimizu W, Kurita T, Suyama K and Kamakura S. Clinical characteristics of patients with spontaneous or inducible ventricular fibrillation without apparent heart disease presenting with J wave and ST segment elevation in inferior leads. J Cardiovasc Electrophysiol 2000;11:844-8.

47. Shinohara T, Takahashi N, Saikawa T and Yoshimatsu H. Characterization of J wave in a patient with idiopathic ventricular fibrillation. Heart rhythm : the official journal of the Heart Rhythm Society. 2006;3:1082-4.

48. Ogawa M, Kumagai K, Yamanouchi Y and Saku K. Spontaneous onset of ventricular fibrillation in Brugada syndrome with J wave and ST-segment elevation in the inferior leads. Heart rhythm. 2005;2:97-9.

49. Komiya N, Imanishi R, Kawano H, Shibata R, Moriya M, Fukae S, Doi Y, Nakao K, Seto S and Yano K. Ventricular fibrillation in a patient with prominent $\mathrm{j}$ wave in the inferior and lateral electrocardiographic leads after gastrostomy. Pacing and clinical electrophysiology : PACE. 2006;29:1022-4.

50. Garg A, Finneran W and Feld GK. Familial sudden cardiac death associated with a terminal QRS abnormality on surface 12-lead electrocardiogram in the index case.J Cardiovasc Electrophysiol 1998;9:642-7.

51. Boineau JP. The early repolarization variant--normal or a marker of heart disease in certain subjects. Journal of electrocardiology. 2007;40:3 e11-6.

52. Haissaguerre M, Derval N, Sacher F, Jesel L, Deisenhofer I, de Roy L, Pasquie JL, Nogami A, Babuty D, Yli-Mayry S, De Chillou C, Scanu P, Mabo P, Matsuo S, Probst V, Le Scouarnec S, Defaye P, Schlaepfer J, Rostock T, Lacroix D, Lamaison D, Lavergne T, Aizawa Y, Englund A, Anselme F, O'Neill M, Hocini M, Lim KT, Knecht S, Veenhuyzen GD, Bordachar P, Chauvin M, Jais P, Coureau G, Chene G, Klein GJ and Clementy J. Sudden cardiac arrest associated with early repolarization. $N$ Engl J Med. 2008;358:2016-23.

53. Nam GB, Kim YH and Antzelevitch C. Augmentation of J waves and electrical storms in patients with early repolarization. The New England journal of medicine. 2008;358:2078-9.

54. Siebermair J, Sinner MF, Beckmann BM, Laubender RP, Martens E, Sattler S, Fichtner S, Estner HL, Kaab S and Wakili R. Early repolarization pattern is the strongest predictor of arrhythmia recurrence in patients with idiopathic ventricular fibrillation: results from a single centre long-term follow-up over 20 years. Europace : European pacing, arrhythmias, and cardiac 
electrophysiology : journal of the working groups on cardiac pacing, arrhythmias, and cardiac cellular electrophysiology of the European Society of Cardiology. 2016;18:718-25.

55. Aizawa Y, Chinushi M, Hasegawa K, Naiki N, Horie M, Kaneko Y, Kurabayashi M, Ito S, Imaizumi T, Aizawa Y, Takatsuki S, Joo K, Sato M, Ebe K, Hosaka Y, Haissaguerre M and Fukuda $\mathrm{K}$. Electrical storm in idiopathic ventricular fibrillation is associated with early repolarization. Journal of the American College of Cardiology. 2013;62:1015-9.

56. Tikkanen JT, Anttonen O, Junttila MJ, Aro AL, Kerola T, Rissanen HA, Reunanen A and Huikuri HV. Long-term outcome associated with early repolarization on electrocardiography. The New England journal of medicine. 2009;361:2529-37.

57. Rollin A, Maury P, Bongard V, Sacher F, Delay M, Duparc A, Mondoly P, Carrie D, Ferrieres J and Ruidavets JB. Prevalence, prognosis, and identification of the malignant form of early repolarization pattern in a population-based study. The American journal of cardiology. 2012;110:1302-8.

58. Merchant FM, Noseworthy PA, Weiner RB, Singh SM, Ruskin JN and Reddy VY. Ability of terminal QRS notching to distinguish benign from malignant electrocardiographic forms of early repolarization. The American journal of cardiology. 2009;104:1402-6.

59. Klatsky AL, Oehm R, Cooper RA, Udaltsova N and Armstrong MA. The early repolarization normal variant electrocardiogram: correlates and consequences. The American journal of medicine. 2003;115:171-7.

60. Perez MV, Uberoi A, Jain NA, Ashley E, Turakhia MP and Froelicher V. The prognostic value of early repolarization with ST-segment elevation in African Americans. Heart rhythm. 2012;9:558-65.

61. Priori SG, Schwartz PJ, Napolitano C, Bloise R, Ronchetti E, Grillo M, Vicentini A, Spazzolini C, Nastoli J, Bottelli G, Folli R and Cappelletti D. Risk stratification in the long-QT syndrome. The New England journal of medicine. 2003;348:1866-74.

62. Priori SG, Napolitano C, Memmi M, Colombi B, Drago F, Gasparini M, DeSimone L, Coltorti F, Bloise R, Keegan R, Cruz Filho FE, Vignati G, Benatar A and DeLogu A. Clinical and molecular characterization of patients with catecholaminergic polymorphic ventricular tachycardia. Circulation. 2002;106:69-74.

63. Mazzanti A, Ng K, Faragli A, Maragna R, Chiodaroli E, Orphanou N, Monteforte N, Memmi M, Gambelli P, Novelli V, Bloise R, Catalano O, Moro G, Tibollo V, Morini M, Bellazzi R, Napolitano C, Bagnardi V and Priori SG. Arrhythmogenic Right Ventricular Cardiomyopathy: Clinical Course and Predictors of Arrhythmic Risk. Journal of the American College of Cardiology. 2016;68:25402550.

64. Derval N, Simpson CS, Birnie DH, Healey JS, Chauhan V, Champagne J, Gardner M, Sanatani S, Yee R, Skanes AC, Gula LJ, Leong-Sit P, Ahmad K, Gollob MH, Haissaguerre M, Klein GJ and Krahn AD. Prevalence and characteristics of early repolarization in the CASPER registry: 
cardiac arrest survivors with preserved ejection fraction registry. Journal of the American College of Cardiology. 2011;58:722-8.

65. Patel RB, Ng J, Reddy V, Chokshi M, Parikh K, Subacius H, Alsheikh-Ali AA, Nguyen T, Link MS, Goldberger JJ, Ilkhanoff $\mathrm{L}$ and Kadish AH. Early repolarization associated with ventricular arrhythmias in patients with chronic coronary artery disease. Circulation Arrhythmia and electrophysiology. 2010;3:489-95.

66. Zhang Z, Letsas KP, Yang Y, Korantzopoulos P, Li G, Yan GX and Liu T. Notching early repolarization pattern in inferior leads increases risk of ventricular tachyarrhythmias in patients with acute myocardial infarction: a meta-analysis. Scientific reports. 2015;5:15845.

67. Kamakura T, Kawata H, Nakajima I, Yamada Y, Miyamoto K, Okamura H, Noda T, Satomi K, Aiba T, Takaki H, Aihara N, Kamakura S, Kimura T and Shimizu W. Significance of non-type 1 anterior early repolarization in patients with inferolateral early repolarization syndrome. Journal of the American College of Cardiology. 2013;62:1610-8.

68. Georgopoulos S, Letsas KP, Liu T, Kalafateli M, Korantzopoulos P, Burkle G, Vlachos K, Giannopoulos G, Efremidis M, Deftereos S, Sideris A, Takagi M, Yan GX and Ehrlich JR. A metaanalysis on the prognostic significance of inferolateral early repolarization pattern in Brugada syndrome. Europace : European pacing, arrhythmias, and cardiac electrophysiology : journal of the working groups on cardiac pacing, arrhythmias, and cardiac cellular electrophysiology of the European Society of Cardiology. 2017.

69. Watanabe H, Makiyama T, Koyama T, Kannankeril PJ, Seto S, Okamura K, Oda H, Itoh H, Okada M, Tanabe N, Yagihara N, Kamakura S, Horie M, Aizawa Y and Shimizu W. High prevalence of early repolarization in short QT syndrome. Heart rhythm. 2010;7:647-52.

70. Macfarlane PW, Antzelevitch C, Haissaguerre M, Huikuri HV, Potse M, Rosso R, Sacher F, Tikkanen JT, Wellens H and Yan GX. The Early Repolarization Pattern: A Consensus Paper. Journal of the American College of Cardiology. 2015;66:470-7.

71. Antzelevitch C, Yan GX, Ackerman MJ, Borggrefe M, Corrado D, Guo J, Gussak I, Hasdemir C, Horie M, Huikuri H, Ma C, Morita H, Nam GB, Sacher F, Shimizu W, Viskin S and Wilde AA. JWave syndromes expert consensus conference report: Emerging concepts and gaps in knowledge. Heart rhythm : the official journal of the Heart Rhythm Society. 2016;13:e295-324.

72. Abe A, Ikeda T, Tsukada T, Ishiguro H, Miwa Y, Miyakoshi M, Mera H, Yusu S and Yoshino H. Circadian variation of late potentials in idiopathic ventricular fibrillation associated with J waves: insights into alternative pathophysiology and risk stratification. Heart rhythm : the official journal of the Heart Rhythm Society. 2010;7:675-82.

73. Sinner MF, Reinhard W, Muller M, Beckmann BM, Martens E, Perz S, Pfeufer A, Winogradow J, Stark K, Meisinger C, Wichmann HE, Peters A, Riegger GA, Steinbeck G, Hengstenberg $C$ and Kaab S. Association of early repolarization pattern on ECG with risk of cardiac and all-cause mortality: a population-based prospective cohort study (MONICA/KORA). PLoS Med. 2010;7:e1000314. 
74. Cristoforetti Y, Biasco L, Giustetto C, De Backer O, Castagno D, Astegiano P, Ganzit G, Gribaudo CG, Moccetti M and Gaita F. J-wave duration and slope as potential tools to discriminate between benign and malignant early repolarization. Heart rhythm. 2016;13:80611.

75. Roten L, Derval N, Maury P, Mahida S, Pascale P, Leenhardt A, Jesel L, Deisenhofer I, Kautzner J, Probst V, Rollin A, Ruidavets JB, Ferrieres J, Sacher F, Heg D, Scherr D, Komatsu Y, Daly M, Denis A, Shah A, Hocini M, Jais P and Haissaguerre M. Benign vs. malignant inferolateral early repolarization: Focus on the T wave. Heart rhythm : the official journal of the Heart Rhythm Society. 2016;13:894-902.

76. Noseworthy PA, Tikkanen JT, Porthan K, Oikarinen L, Pietila A, Harald K, Peloso GM, Merchant FM, Jula A, Vaananen H, Hwang SJ, O'Donnell CJ, Salomaa V, Newton-Cheh C and Huikuri HV. The early repolarization pattern in the general population: clinical correlates and heritability. Journal of the American College of Cardiology. 2011;57:2284-9.

77. Nunn LM, Bhar-Amato J, Lowe MD, Macfarlane PW, Rogers P, McKenna WJ, Elliott PM and Lambiase PD. Prevalence of J-point elevation in sudden arrhythmic death syndrome families. Journal of the American College of Cardiology. 2011;58:286-90.

78. Reinhard W, Kaess BM, Debiec R, Nelson CP, Stark K, Tobin MD, Macfarlane PW, Tomaszewski M, Samani NJ and Hengstenberg C. Heritability of early repolarization: a population-based study. Circulation Cardiovascular genetics. 2011;4:134-8.

79. Gourraud JB, Le Scouarnec S, Sacher F, Chatel S, Derval N, Portero V, Chavernac P, Sandoval JE, Mabo P, Redon R, Schott JJ, Le Marec H, Haissaguerre M and Probst V. Identification of large families in early repolarization syndrome. Journal of the American College of Cardiology. 2013;61:164-72.

80. Barajas-Martinez H, Hu D, Ferrer T, Onetti CG, Wu Y, Burashnikov E, Boyle M, Surman T, Urrutia J, Veltmann C, Schimpf R, Borggrefe M, Wolpert C, Ibrahim BB, Sanchez-Chapula JA, Winters S, Haissaguerre $\mathrm{M}$ and Antzelevitch $\mathrm{C}$. Molecular genetic and functional association of Brugada and early repolarization syndromes with S422L missense mutation in KCNJ8. Heart rhythm : the official journal of the Heart Rhythm Society. 2012;9:548-55.

81. Medeiros-Domingo A, Tan BH, Crotti L, Tester DJ, Eckhardt L, Cuoretti A, Kroboth SL, Song C, Zhou Q, Kopp D, Schwartz PJ, Makielski JC and Ackerman MJ. Gain-of-function mutation S422L in the KCNJ8-encoded cardiac K(ATP) channel Kir6.1 as a pathogenic substrate for J-wave syndromes. Heart rhythm : the official journal of the Heart Rhythm Society. 2010;7:1466-71.

82. Burashnikov E, Pfeiffer R, Barajas-Martinez H, Delpon E, Hu D, Desai M, Borggrefe M, Haissaguerre M, Kanter R, Pollevick GD, Guerchicoff A, Laino R, Marieb M, Nademanee K, Nam GB, Robles R, Schimpf R, Stapleton DD, Viskin S, Winters S, Wolpert C, Zimmern S, Veltmann C and Antzelevitch C. Mutations in the cardiac L-type calcium channel associated with inherited Jwave syndromes and sudden cardiac death. Heart rhythm : the official journal of the Heart Rhythm Society. 2010;7:1872-82. 
83. Hu D, Barajas-Martinez H, Pfeiffer R, Dezi F, Pfeiffer J, Buch T, Betzenhauser MJ, Belardinelli L, Kahlig KM, Rajamani S, DeAntonio HJ, Myerburg RJ, Ito H, Deshmukh P, Marieb M, Nam GB, Bhatia A, Hasdemir C, Haissaguerre M, Veltmann C, Schimpf R, Borggrefe M, Viskin S and Antzelevitch C. Mutations in SCN10A are responsible for a large fraction of cases of Brugada syndrome. Journal of the American College of Cardiology. 2014;64:66-79.

84. Watanabe H, Nogami A, Ohkubo K, Kawata H, Hayashi Y, Ishikawa T, Makiyama T, Nagao S, Yagihara N, Takehara N, Kawamura Y, Sato A, Okamura K, Hosaka Y, Sato M, Fukae S, Chinushi M, Oda H, Okabe M, Kimura A, Maemura K, Watanabe I, Kamakura S, Horie M, Aizawa Y, Shimizu W and Makita N. Electrocardiographic characteristics and SCN5A mutations in idiopathic ventricular fibrillation associated with early repolarization. Circulation Arrhythmia and electrophysiology. 2011;4:874-81.

85. Rosso R, Adler A, Halkin A and Viskin S. Risk of sudden death among young individuals with J waves and early repolarization: putting the evidence into perspective. Heart rhythm : the official journal of the Heart Rhythm Society. 2011;8:923-9. 